\title{
LA PÉRDIDA DE LA TENENCIA POR ALIENACIÓN PARENTAL
}

\author{
LOSS OF CUSTODY DUE TO PARENTAL ALIENATION
}

\author{
Vanessa Elizabeth Shinno Pereyra ${ }^{1}$ \\ Universidad de Lima \\ Lima, Perú \\ https://orcid.org/0000-0001-6052-1834 \\ vanessa.shinno@gmail.com
}

\begin{abstract}
RESUMEN
El presente trabajo centra sus objetivos en analizar el síndrome de alienación parental que recae en la sentencia de la Segunda Sala Civil de Ica: 00075-2012-0-1401-JR-FC-01 donde se comprobó el daño a la integridad del menor de edad; por lo que, la progenitora, quien no posee la tenencia, puede solicitar su variación con el propósito de evidenciar con medios probatorios idóneos tener la custodia y que el otro progenitor la pierda.
\end{abstract}

\section{PALABRAS CLAVES}

Patria potestad, tenencia, síndrome de alienación parental, interés superior del niño.

\section{ABSTRACT}

The purpose of this paper is to analyze the parental alienation syndrome examined in the judgment handed down by the Second Civil Court of Ica: 00075-2012-01401-JR-FC-01, where the child's integrity was proven to be damaged. This fact entitled the mother, who did not have custody, to request its change. To this end, suitable evidence was exhibited to obtain custody and for the other parent to lose it.

\section{KEYWORDS}

Parental rights, custody, parental alienation syndrome, child's best interest.

\section{INTRODUCCIÓN}

La alienación parental consiste en la influencia indebida y negativa que provoca un progenitor hacia su hijo o hija con el propósito de rechazar el cariño y cuidado del otro progenitor, ello se origina a raíz de las disputas de los progenitores por la tenencia de sus hijos; en ese sentido, se obstaculiza el vínculo de la relación paternofilial, a tal punto de quebrarla definitivamente. De lo expuesto, se analizará una sentencia judicial emitida por la Segunda Sala Civil de Ica en la que el progenitor alienante pierde la tenencia al haber provocado, en su menor hijo, la alienación parental, a pesar de existir un acuerdo conciliatorio a su favor, pues la Sala determinó que se vulneró el interés superior del niño; asimismo, ordenó la suspensión de la tenencia y custodia al progenitor alienante; y, realizar terapias psicológicas para que las relaciones familiares se reconstruyan y fortalezcan.

1 Abogada y egresada de la Universidad de Lima. Doctorando en Derecho por la Universidad Nacional Mayor de San Marcos. Maestro en Derecho Civil con mención en Derecho de Familia por la Universidad Femenina del Sagrado Corazón. Registrada en CTI Vitae. Docente de la Facultad de Derecho de la Universidad Peruana de Ciencias Aplicadas. Docente de la Facultad de Derecho de la Universidad Continental. 


\section{PATRIA POTESTAD}

Para empezar, se va a analizar la figura jurídica de la patria potestad con el propósito de conocer que los padres son los que la van a ejercer de manera conjunta y que de ello se deriva la tenencia.

La patria potestad es la institución jurídica del derecho de familia que abarca un conjunto de deberes y derechos donde la ley otorga la facultad a los padres para el cuidado personal de sus hijos, así como también administrar su patrimonio hasta alcanzar la mayoría de edad; por lo que, tiene la finalidad de lograr el desarrollo integral de los menores de edad.

Adicionalmente, se considera lo siguiente:

Esta institución está ligada a la filiación, y nace en el momento mismo en que se establece la relación paternofilial mediante su inscripción en el Registro Civil al nacimiento del menor, tras una sentencia que declare la filiación, por presunción de paternidad matrimonial o, en su defecto, por posesión de estado. (López, 2020, p. 2)

Por un lado, es un deber porque los padres tienen la obligación de cuidar a sus hijos, criarlos, asistirlos, entre otras obligaciones; por otro lado, es un derecho puesto que tienen la facultad de mantener comunicación con sus hijos, compartir su desarrollo, entre otros que se encuentran regulados en el artículo 423 del Código Civil, en concordancia con el artículo 74 del Código de los Niños y Adolescentes.

En ese sentido, se concuerda con esta postura:

Esta relación tutelar se inicia con la concepción y termina con la adquisición de la capacidad de los hijos. Como es lógico, desde el momento de la concepción surge un sujeto de derecho que merece la más amplia protección en su aspecto sicosomático como el de su peculio. Esta protección y defensa tutelar, que corresponde a los padres, se acabará cuando el sujeto de derecho consiga la capacidad para poder defenderse por sí mismo y administrar su patrimonio. (Varsi, 2012, p. 291)

De lo expuesto, se puede concluir que la patria potestad es derivada de la filiación puesto que, a partir de ella, surge la relación paterno filial donde abarca las relaciones jurídicas, especialmente, de autoridad entre padres sobre sus hijos y así poder no solo cuidar de la persona del hijo sino también administrar sus bienes y representarlos en asuntos de la vida cotidiana.

Por último, la patria potestad presenta las siguientes características:

Tabla 1: Características de la patria potestad

\begin{tabular}{|l|l|}
\hline Intransmisible & Solo los padres la poseen. \\
\hline Temporal & Puede extinguirse o perderse. \\
\hline Irrenunciable & Admitirlo sería omitir los deberes paternofiliales. \\
\hline Indisponible & Fuera de todo comercio. \\
\hline Tuitivo & Protección del menor y cuidados respectivos. \\
\hline
\end{tabular}

Fuente: Elaboración propia 


\section{TENENCIA}

La tenencia es el atributo de la patria potestad que consiste en tener a los hijos bajo la custodia del progenitor o progenitores e incluso se puede otorgar la tenencia a los abuelos ya sea paternos o maternos para salvaguardar el interés superior del niño; en ese sentido, permite fortalecer las relaciones familiares. De esta forma se efectivizará el desarrollo holístico del niño, vale decir en el aspecto moral, espiritual, psicológico; entre otros.

Por consiguiente, la tenencia se conceptualiza de la siguiente manera:

La tenencia se traduce en la convivencia de los padres con sus hijos; relación que sirve de base para el ejercicio de los demás derechos y el cumplimiento de los deberes, es decir la vida en común, lo que significa vivir bajo un mismo techo. Estas relaciones personales (padres e hijos) son toda la base para que operen los demás atributos de la patria potestad, ya que si el padre o madre no ejerce la llamada tenencia, cómo se podría estar frente a un proceso educativo, cómo podría representarlo legalmente, o cómo podría ejercer una corrección moderada, sólo para mencionar algunos de los atributos que confiere la patria potestad. (Aguilar, 2009, p. 192)

En síntesis, se traduce en el deber-derecho entre padres e hijos; en otras palabras, es un derecho de los padres en tener bajo su custodia el cuidado de los menores y también es un deber de los hijos en vivir bajo el mismo techo con sus padres donde no pueden alejarse si ningún tipo de autorización; en conclusión, la tenencia faculta a los padres a recogerlos en el lugar donde se encuentran; y, solicitar a la autoridad competente en caso de la comisión de delitos como la sustracción de menor, instigación a la fuga del menor que se encuentran regulados dentro del Código Penal.

Otra definición que se le puede brindar a esta institución jurídica se traduce en:

Es una relación jurídica familiar básica que se identifica como un derecho-deber de tener en custodia a un hijo. Como derecho familiar subjetivo reconoce, en este orden de ideas, el derecho del progenitor de cuidar al hijo así como, recíprocamente, el derecho del hijo de vivir con el padre que mejor condición de vida le ofrezca. En otras palabras, no es una facultad exclusiva del progenitor, sino que es una facultad indispensable del hijo para su desarrollo integral. (Varsi, 2012, p. 304)

Entonces, se puede advertir que la tenencia, al ser un atributo de la patria potestad, permite a los progenitores convivir con sus hijos bajo un mismo hogar y brindarles afecto, cariño, así como también cuidarlos para evitar el detrimento y menoscabo del interés superior del niño. Por otro lado, existen tipos de tenencia y son las siguientes:

Tabla 2: Tipos de tenencia

\begin{tabular}{|c|l|}
\hline Tenencia unipersonal & $\begin{array}{l}\text { Uno de los progenitores la posee ya sea por acuerdo conciliatorio o sentencia } \\
\text { judicial. }\end{array}$ \\
\hline Tenencia compartida & Ambos progenitores comparten al mismo tiempo la tenencia de sus hijos. \\
\hline Tenencia provisional & $\begin{array}{l}\text { Medida cautelar donde el padre o madre quien no tenga el hijo bajo su custodia } \\
\text { solicita al juez en caso si estuviera en peligro su integridad. }\end{array}$ \\
\hline
\end{tabular}

Fuente: Elaboración propia 
Por último, en cuanto a cómo se determina la tenencia el artículo 84 del Código de los Niños y Adolescentes advierte:

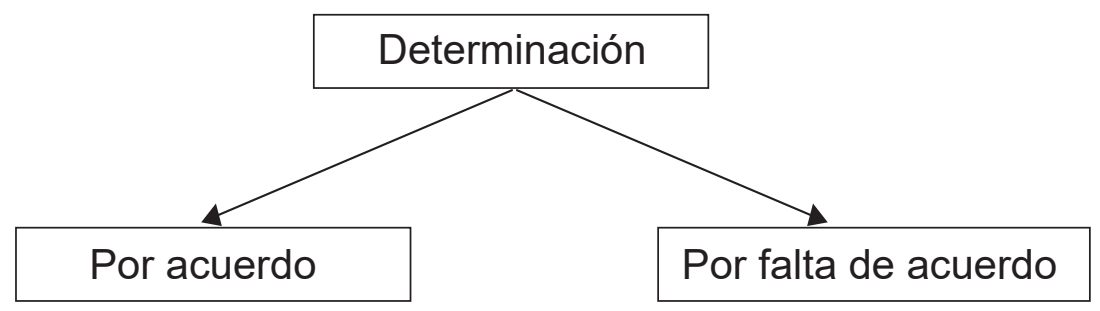

Fuente: Elaboración propia

De lo esbozado en la figura, cuando se medie acuerdo implica el consentimiento, acuerdo de voluntades de ambos padres tomando en cuenta la opinión del niño, niña o adolescente con el objetivo de expresar lo que sienten, en base al interés superior del niño y así garantizar el desarrollo integral de aquél; vale decir, el desarrollo holístico en los aspectos físicos, psicológicos, morales, etc.

No obstante, cuando no exista acuerdo, intervendrá el juez de familia para solucionar el conflicto de intereses y establecerá quién tendrá la tenencia o sino dispone la tenencia compartida, todo ello en base al interés superior del niño; pues, el juez puede disponer que la tenencia sea dada a los abuelos, acorde con las siguientes casaciones citadas por Varsi (Varsi, 2012, p. 306-307):

* Casación N²7744-2006-La Libertad²: Ni el a quo ni el ad quem han desconocido la patria potestad que corresponde al actor como padre respecto de la menor cuya tenencia reclama a través de la presente demanda, sino que, pese a ello, han estimado que en aplicación del interés superior del niño no puede ser ejercido en este caso, dado que lo más beneficioso para el desarrollo integral de dicha menor es que continúe bajo el cuidado de su abuela materna.

* Casación N 4881-2009-La Libertad3: "Corresponde la tenencia y tutela del menor a favor de los abuelos maternos en la medida que alejar a la menor de estos -quienes desde la muerte de la madre se han encargado de crear un vínculo afectivo con ella, siendo las únicas personas con quienes ha mantenido contacto y le han dado atenciones y cuidado que todo niño necesita- implicaría una alteración a su desarrollo emocional y social, lo cual se contradice con el interés superior del niño.

Por último, cabe resaltar que el proceso judicial de tenencia se realiza dentro del proceso único cuyo juez competente es el juez de familia, siempre y cuando los padres se encuentren separados de hecho y no exista acuerdo sobre la tenencia.

\section{ALIENACIÓN PARENTAL}

Consiste en un trastorno que se caracteriza por el conjunto de síntomas por el cual un progenitor, denominado alienante, modifica, influencia la conciencia de sus hijos de manera indebida, mediante diversas formas con el propósito de impedir e incluso destruir los vínculos afectivos que posee con el otro progenitor; por otro lado, la OMS (Organización Mundial de la Salud) no reconoce que

2 Casación $N^{\circ}$ 4774-2006-La Libertad.

3 Casación N4881-2009-La Libertad. 
la alienación parental sea un síndrome; por lo que, elimina de su índice de clasificación; así lo expone el periódico digital progresista: El Plural (2020) donde refiere que el término de "síndrome" es utilizado para asuntos judiciales.

Por su parte Rodríguez (2011), sobre la alienación parental, indica:

El término se refiere a la conducta llevada a cabo por el padre o madre que conserva bajo su cuidado al hijo(a) y realiza actos de manipulación con la finalidad de que el menor de edad odie, tema o rechace injustificadamente al progenitor que no tiene su custodia legal. El tema de la alienación parental se ha pensado de manera más frecuente en casos de separación de parejas y divorcio, sin embargo, es posible identificarlo en parejas que aún no han iniciado ese proceso (p. 53).

De igual modo, Ruiz (2011) sostiene:

Hay incluso otro sector doctrinal que considera que la alienación parental es un tipo de maltrato infantil, en el que considera que los profesionistas de la abogacía, de la judicatura, del peritaje, entre otros, adquieren responsabilidad en su continuidad. Al efecto, señalan que la negativa de los hijos adquiere auténtica trascendencia cuando se expresa en un juzgado, ya que se desencadenan entonces acusaciones, búsquedas de explicaciones y acciones encaminadas a resolver el problema que hace que la instancia judicial se convierta en parte para resolver el mismo, de tal manera que debamos incluirla como un elemento de vital importancia de los componentes del Síndrome (p. 133).

De lo expuesto, se advierte que dichos autores no utilizan el término "síndrome" porque se ajusta a lo dispuesto por la OMS; sin embargo, trasladándose al ámbito nacional, los jueces y juristas nacionales utilizan este término porque se va a enlazar a la sentencia de la Segunda Sala Civil de Ica: 00075-2012-0-1401-JR-FC-01 que vendría hacer un asunto judicial; y, que provoca un daño psicológico que realiza uno de los padres en contra de su hijo.

Para dilucidar con profundidad este concepto, se advierte lo siguiente:

El síndrome de alienación parental (SAP) es un trastorno que se presenta en la niñez y que surge casi exclusivamente en el contexto de una disputa por la custodia del niño. Su manifestación primaria es una campaña de denigración de un progenitor anteriormente querido por el niño, a la que se agregan elementos que el propio niño aporta para alejarse cada vez más del progenitor alienado. (Maida, Herskovic y Prado, 2011, p. 486).

De lo esbozado, se considera que este desorden conlleva a que los menores de edad opten por el menosprecio profundo hacia su progenitor a tal punto de destruir completamente los vínculos afectivos; y, muy aparte de ello, trae como consecuencia disturbios psicológicos, cuadros de ansiedad, baja autoestima y otros factores que afectan la integridad personal, psíquica y la salud mental de los menores de edad.

Los síntomas más usuales que se presenta en el SAP son: 
Tabla 3: Síntomas del SAP

\begin{tabular}{|c|}
\hline $\begin{array}{c}\text { Impedimento de uno de los progenitores a que el otro ejerza el derecho de relacionamiento } \\
\text { con sus hijos. }\end{array}$ \\
\hline Depreciar e insultar al otro progenitor en presencia del hijo. \\
\hline Denigrar la imagen del progenitor. \\
\hline Interferir en el régimen de visitas. \\
\hline Subestimar los sentimientos de los hijos hacia el otro progenitor. \\
\hline Incentivar o premiar el rechazo hacia el otro progenitor. \\
\hline Obligar al hijo a optar entre el padre o madre. \\
\hline
\end{tabular}

Fuente: Varsi, E. (2012) Tratado de Derecho de Familia. Tomo III. Página: 385.

En consecuencia, son los propios progenitores los responsables en hacer frente a estas inconductas que dañan la salud mental de sus hijos.

Asimismo, existen grados donde se manifiesta el síndrome de alienación parental que según Monge (2011) citado por Herrera (2017, p. 68-69) se tiene:

a) Grado I.-Leve: Las manifestaciones de denigración que posee el hijo alienado con el otro progenitor desaparecen y no persisten en el tiempo.

b) Grado II.-Moderado: El progenitor alienante utiliza varias tácticas para excluir al otro progenitor; sin embargo, los hijos alienados aún guardan cariño hacia su otro progenitor.

c) Grado III.-Severo: Los hijos alienados se encuentran en un cuadro de pánico por la idea de visitar a su otro progenitor a tal punto que empiezan a ser violentos; por lo que las visitas se tornan en imposible.

En ese sentido, para combatir el síndrome de alienación parental los hijos alienados deben realizar tratamiento especializado con psicólogos o psiquiatras; entonces, para ello, se sugiere:

En casos leves a moderados de SAP, se puede intentar una intervención psicoterapéutica, implementando mediación o terapia sistémica. El mediador requiere conocer bien el cuadro de SAP, entender los motivos del padre alienante y estar atento al engaño y mentira que hay en estos casos. El niño puede ser atendido, sesión por medio, con cada uno de los padres. Los niños muy alienados requieren intervenciones terapéuticas intensivas, con aproximaciones sucesivas hacia el padre rechazado para reconstruir la relación y el apoyo de los tribunales para que esta situación se produzca. Otra forma de intervención judicial puede ser la obligación de tener períodos de residencia prolongados con el padre alienado, además de la terapia. (Maida, Herskovic y Prado, 2011, p. 490).

Adicionalmente, algunas estrategias preventivas para fortalecer a las familias y evitar que los menores sean perjudicados por la alienación parental, según Gil (2011) son:

- Asegurar la vida y el crecimiento de los menores de edad. La experiencia que permite nutrir está dada por el apego seguro y la capacidad de empatía.

- Contribuir a formar la identidad sana, derivado de un entorno humano de buenos tratos que facilite la socialización. 
- Permitir a los menores de edad ser capaces de convivir en la familia y sociedad, respetándose a sí mismos y a los demás, a partir de la coherencia y la pertinencia entre lo que piensan, dicen y hacen.

- Fomentar la seguridad que permita reducir el estrés psicológico, proveniente de un entorno poco favorable.

- Establecer vínculos entre los padres u otras personas responsables del cuidado y protección de los menores, originando una experiencia de familiaridad que implica ser aceptados para tener como base la confianza y el reconocimiento.

- Promover la capacidad de pensar y reflexionar para que aprendan a relacionarse con su medio, apoyando los esfuerzos y los logros que obtengan. (p. 282)

De esta forma, se evitará a futuro que las relaciones paterno-materno filiales se destruyan completamente y que los menores de edad puedan disfrutar y gozar su niñez como corresponda; ya que, la alienación parental es una forma de maltrato infantil.

Por otro lado, algunos investigadores consideran que la alienación parental debe ser tipificado como delito porque conlleva a la vulneración de los derechos fundamentales y que causa perjuicio irreparable al otro progenitor, acorde a las encuestas realizadas a los operadores jurídicos:

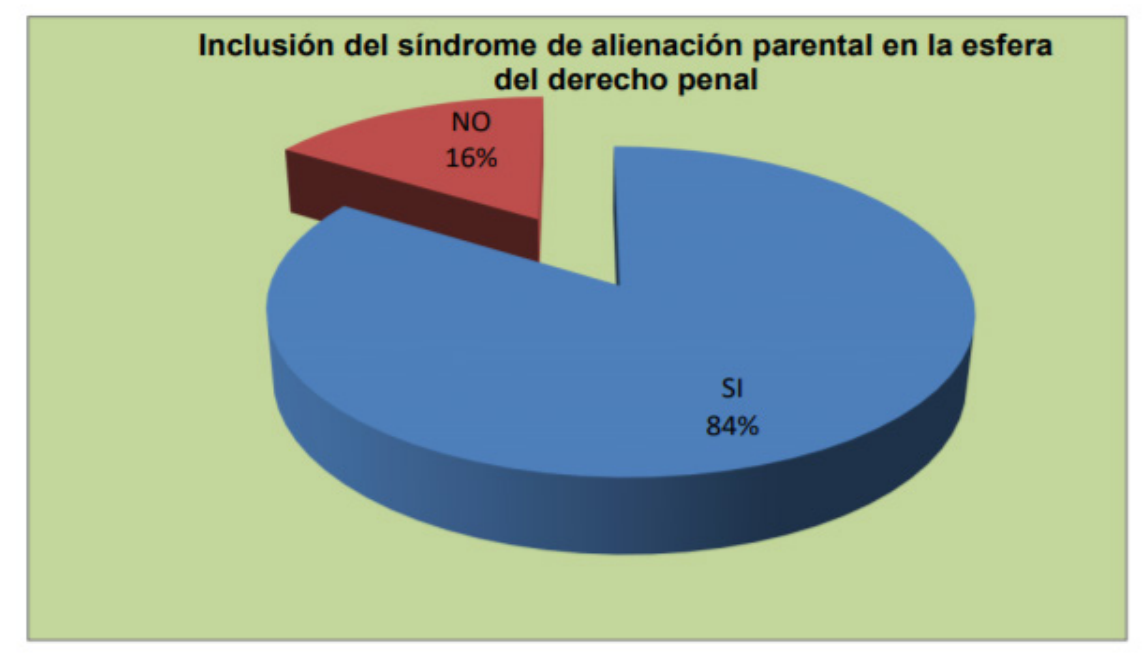

Fuente: Chávez, S. (2018) Síndrome de alienación parental en el derecho penal peruano, como factor positivo contra la violencia psicológica. Página: 81.

De lo expuesto, se puede apreciar que el $84 \%$ de los jueces encuestados indica que se debe tipificar como delito penal el síndrome de alienación parental; mientras, el 16\% consideran que no es necesario incluirlo dentro del derecho penal.

En conclusión, la alienación parental es un aspecto de maltrato infantil generalmente un comportamiento de violencia psicológica por lo que puede ser reducido a través de un tratamiento terapéutico pertinente; sin embargo, la ley civil opera mecanismos para sancionar a los progenitores alienantes como la pérdida de la tenencia e incluso la suspensión de la patria potestad; en ese sentido, no habría que tipificarlo como delito pues existen vías alternas para poder aplicar las sanciones; ya que el derecho penal se aplica como última ratio. 


\section{INTERÉS SUPERIOR DEL NIÑO}

Se advierte que es principio vinculante para todos aquéllos que pretendan tomar decisiones respecto a circunstancias o aspectos en la que deban resolverse conflictos que afecten a niños, niñas o adolescentes; por consiguiente, se consagra como un principio inspirador, que sirve para la solución de conflictos de interés entre un niño y el interés de un adulto, donde se priorizará los intereses del niño porque es un sujeto de derecho con capacidad especial; debido a que se encuentra en situación de vulnerabilidad; por lo que este principio favorece la protección de los derechos del niño.

Por lo tanto, corresponderá a los Estados velar, salvaguardar, proteger los derechos de los niños, niñas y adolescentes que se encuentren vulnerados o amenazados sus derechos; de esta forma, se permitirá el goce y disfrute de los mismos; adicionalmente a ello, dicho principio sera una consideración primordial.

De lo expuesto, el principio del interés superior del niño es la premisa fundamental de la doctrina de la protección integral; vale decir, es la base para la interpretación y aplicación de la normativa para los niños, niñas y adolescentes.

Es así como el Expediente N. ${ }^{\circ} 02079-2009^{4}$, refiere lo siguiente:

El deber especial de protección sobre los Derechos del Niño vincula no sólo a las entidades estatales y públicas sino también a las entidades privadas e inclusive a la comunidad, a fin de que en cualquier medida que adopten o acto que los comprometa velen por el interés superior del niño, el cual debe anteponerse a cualquier otro interés. Por tanto, constituye un deber el velar por la vigencia de los derechos del niño y la preferencia de sus intereses, resultando que ante cualquier situación en la que colisione o se vea en riesgo el interés superior del niño, indudablemente, este debe ser preferido antes que cualquier otro interés. Y es que la niñez constituye un grupo de personas de interés y de protección prioritaria del Estado y de toda la comunidad, por lo que las políticas estatales le deben dispensar una atención preferente. (Fundamento jurídico 13).

En ese orden de ideas, establece que ante algún menoscabo frente al supuesto interés de un adulto sobre el del niño, prevalece el de este último; esto se da por la necesidad de defender los derechos de quien no puede ejercerlos personalmente por sí mismo y de quien, por la etapa de desarrollo en que se encuentra, no puede oponer resistencia o responder ante alguna lesión a sus derechos.

Por otro lado, el objetivo del concepto de interés superior del niño es garantizar el disfrute pleno y efectivo de todos los derechos reconocidos por la Convención y el desarrollo integral del niño, es decir, implica el desarrollo físico, moral, espiritual, psicológico, mental y social del niño. De acuerdo con la Observación General N. ${ }^{0} 14$ (2013, p. 4), aprobada por el Comité, subraya que el interés superior del niño es un concepto triple:

Un derecho sustantivo: el derecho del niño a que su interés superior sea una consideración primordial que se evalúe y tenga en cuenta al sopesar distintos intereses para tomar una

4 Exp.N02079-2009. Sala Primera del Tribunal Constitucional. Distrito Judicial de Lima. Fundamento jurídico 13 
decisión sobre una cuestión debatida, y la garantía de que ese derecho se pondrá en práctica siempre que se tenga que adoptar una decisión que afecte a un niño, a un grupo de niños concreto o genérico o a los niños en general.

$\checkmark$ Un principio jurídico interpretativo fundamental: si una disposición jurídica admite más de una interpretación, se elegirá la interpretación que satisfaga de manera más efectiva el interés superior del niño.

$\checkmark$ Una norma de procedimiento: siempre que se tenga que tomar una decisión que afecte a un niño en concreto, a un grupo de niños concreto o a los niños en general, el proceso de adopción de decisiones deberá incluir una estimación de las posibles repercusiones (positivas o negativas) de la decisión en el niño o los niños interesados. Además, la justificación de las decisiones debe dejar patente que se ha tenido en cuenta explícitamente ese derecho. En este sentido, los Estados parte deberán explicar cómo se ha respetado este derecho en la decisión, es decir, qué se ha considerado que atendía al interés superior del niño, en qué criterios se ha basado la decisión y cómo se han ponderado los intereses del niño frente a otras consideraciones, ya se trate de cuestiones normativas generales o de casos concreto.

En conclusión, a raíz de la Observación General N 14 en la legislación nacional se promulgó la Ley 30466 que establece parámetros y garantías procesales para la consideración primordial del interés superior del niño, donde el artículo 2 reconoce que es un principio, derecho y norma de procedimiento, tomando aspectos de esta observación general en cuanto a sus parámetros y garantías procesales; por otro lado, se promulgó el reglamento de esta ley donde reconoce medidas legislativas, planes, diseño de políticas públicas para garantizar los derechos de los niños, niñas y adolescentes.

\section{ANÁLISIS DE LA SENTENCIA DE LA SEGUNDA SALA CIVIL DE ICA: 00075-2012}

Una vez esbozado y analizado la patria potestad, la tenencia, la alienación parental y el interés superior del niño, se procederá a analizar la sentencia en mención, partiendo de los hechos más relevantes:

El recurrente interpuso demanda de tenencia y custodia de su menor hijo por ofrecerle buenas condiciones de vida, en contra de la demandada quien hizo abandono de hogar y que fue ella misma quien hizo entrega del menor mediante declaración jurada e incluso no acreditó estar al día en las pensiones alimenticias.

La demandada contestó la demanda pero de manera extemporánea y afirmó que el demandante no prestaba facilidades para que pueda visitar a su menor hijo; seguidamente, el juez solicitó la presencia del equipo multidisciplinario para que realice visitas sociales en el hogar de los progenitores con el propósito de practicar evaluaciones psicológicas tanto a los padres como al menor de edad.

Por otro lado, se adjuntó como medios probatorios la transacción extrajudicial donde se llegó a un acuerdo sobre tenencia, régimen de visitas y alimentos, en la que se arribó que el menor de edad quedaría bajo la custodia de la demandada; y, que se fijó a favor demandante el régimen de visitas.

Posteriormente, se realizó un acta de conciliación extrajudicial donde se hizo constar que la demandada cedía la tenencia de su menor hijo a favor del accionante, para que viva con él; adicionalmente, se acordó que en caso de incumplimiento automáticamente la demandada asumiría la tenencia del menor. 
Cuando se realizó la evaluación psicológica al menor de edad, se dejó constancia que el menor vive con su abuelo paterno y con una tía paterna siendo ésta última la que lo cuida; mientras que su padre trabaja como profesor y sólo viene a verlo los sábados y domingos; y que no ve a su madre; por lo que se concluye que el menor se encuentra con síndrome de alienación parental, pues demuestra negatividad al cariño de su madre y los demás familiares han logrado conducir que el niño desprecie la presencia y el acercamiento de su madre; por lo que el psicólogo ha recomendado que el padre alimente a su hijo con cariño y afecto hacia su madre.

El juez de primera instancia declaró infundada la demanda por el informe psicológico practicado al menor y a su padre pues se evidenció el síndrome de alienación parental; adicionalmente, dispuso la tenencia y custodia del menor a favor de su madre donde ordenó que el demandante haga entrega del menor a su progenitora; asimismo, estableció como régimen de visitas a favor del demandante; sin embargo, el demandante interpuso recurso de apelación y la Sala Civil revocó la sentencia apelada porque se vulneró el principio del interés superior del niño y confirmó la suspensión de la tenencia y custodia del padre respecto de su menor hijo.

De lo expuesto, se analizará algunos considerandos relevantes de dicha Sala. Se advierte que el considerando quinto inciso 1, expresa lo siguiente:

La tenencia es la situación por la cual un menor se encuentra en poder de uno de sus padres o guardadores, es uno de los derechos que tienen los padres de tener a sus hijos en su compañía; sin embargo, por extensión la tenencia puede otorgársele a quien tenga legítimo interés. La tenencia es además de un derecho, un estado físico de dependencia del menor con respecto a uno de sus padres (o respecto a alguien con legítimo interés); es una institución familiar que se instituye cuando los padres están separados de hecho o de derecho, con el fin de establecer con quien se quedan los hijos y además establecer el régimen de visitas para el padre que no obtenga la tenencia. Esto por el mérito de lo previsto en los artículos $83^{\circ}$ y $88^{\circ}$ último párrafo del Código de los Niños y Adolescentes, que prescriben expresamente que, "el padre o la madre ... que desee que se le reconozca el derecho la custodia y tenencia de su hijo, interpondrá su demanda acompañando el documento que lo identifique, la partida de nacimiento y las pruebas pertinentes ...", y que "... el Juez, respetando en lo posible, el acuerdo de los padres, dispondrá un Régimen de Visitas adecuado al Principio del Interés Superior del Niño y del Adolescente y podrá variarlo de acuerdo a las circunstancias en resguardo de su bienestar ...". (Expediente 00075-2012, p. 3-4)

En ese sentido, la tenencia es uno de los atributos de la patria potestad en la que el progenitor tiene bajo su custodia compartiendo con él dentro de un mismo hogar; por lo que es un deber y derecho que permitirá el desarrollo de las relaciones paterno-materno filiales. Cabe resaltar que el artículo 81 del Código de los Niños y Adolescentes establece la determinación de la tenencia donde mediará por acuerdo o sino ante una instancia judicial para que el juez de familia decida quién deba poseer la tenencia o si no disponer la tenencia compartida.

Siguiendo en la misma línea; y, de conformidad con Aguilar (2009) señala:

Ahora bien, cuando hemos definido la tenencia, hemos hecho hincapié en la convivencia de los padres con sus hijos, entonces la tenencia tiene que verse desde dos vertientes, una la de los padres, como derecho de ellos de vivir con sus hijos, y la segunda referida a los hijos, como derechos de ellos de vivir con ambos padres ... En consecuencia este 
derecho de tenencia no debe ser visto sólo como un derecho a reclamar por parte de los padres, sino que en su concesión debe tenerse presente el derecho de los niños a vivir con sus padres, por lo tanto, la opinión de ellos (en el caso de que estén en posibilidades de hacerlo) resulta siendo importante, y aun cuando su desarrollo evolutivo no le permitiera formarse su propia opinión, habría que considerar fundamentalmente los intereses de éstos antes de que se pronuncien sobre esta tenencia. (p.193)

Por consiguiente, este deber y derecho entre padres e hijos permitirá fortalecer las relaciones familiares para que de esa manera se efectivice el desarrollo holístico del menor de edad; es decir, en el aspecto psicológico, emocional, personal, entre otros con la finalidad que los niños, niñas y adolescentes puedan crecer y vivir de manera armónica con sus progenitores brindándoles cariño, afecto, solidaridad buscando lo mejor para ellos.

Por otro lado, el considerando octavo inciso 2 refiere:

En cuanto al síndrome de alienación parental se dice que consiste en el proceso destinado a romper el vínculo de los hijos con uno de sus progenitores. Es un fenómeno desencadenado por uno de los padres (generalmente la madre) en contra del otro progenitor (generalmente el padre), que surge en el contexto de las disputas por la custodia del hijo con una campaña de denigración de este último que se despliega sobre el niño, llevada a cabo por el adoctrinamiento y la propia contribución del niño en el vilipendio de la imagen parental afectada. Esta circunstancia es provocada por el progenitor alienador mediante un mensaje y un programa, que constituyen lo que normalmente se denomina "lavado de cerebro". De esta manera, los hijos sufren esta alienación parental desarrollan un odio patológico e injustificado hacia el progenitor alienado que tiene consecuencias devastadoras en el desarrollo físico y psicológico de éstos. Consecuentemente, la alienación parental afecta también a los familiares del progenitor alienado como son: sus abuelos, tíos, primos, etc. Por eso, la alienación parental está considerada como una forma de maltrato infantil desde que es una estrategia desquiciante del progenitor orientador del rechazo, quien al cometer esta acción fortalece la negativa de los hijos de ver al otro padre, efectuando acusaciones sin ningún tipo de prueba legal; afectando gravemente el psiquismo de los hijos. (Expediente $\mathrm{N}^{\circ} 00075-2012$, p. $\left.7-8\right)$

Efectivamente, la alienación parental genera un trastorno mental al menor de edad a tal punto de despreciar el cariño y afecto del otro progenitor por las influencias indebidas del progenitor alienante; y, en concordancia con Herrera (2017) se concluye:

La alienación parental viene a ser un proceso donde uno de los progenitores influye (programa) al hijo con la finalidad de que se ponga en contra del otro progenitor, manifestándole odio y rechazo, sin que existe justificación para ello. Cuando el síndrome se produce, el hijo comienza a dar su propia contribución en esta campaña de denigración en contra del padre rechazado. (p. 67)

Adicionalmente, se comparte lo siguiente:

Debe solicitarse al equipo multidisciplinario del módulo de familia una evaluación que determine en forma específica y expresa si los menores son víctimas de Síndrome de Alienación Parental, una evaluación a los padres en cuanto a su tendencia a la manipulación, y de concluir los peritos en que efectivamente hay un padre manipulador 
y un niño manipulado para enfrentarse al otro progenitor, éstos deberán ser sometidos a una terapia psicológica que ordene el Juzgado. Entonces, el juez y el fiscal tendrán un elemento objetivo más que coadyuve a un pronunciamiento integral y justo, valorándose en su real dimensión la conducta del progenitor alienador, teniendo presente que esta conducta manipuladora y egoísta, en ningún caso será favorable para el menor de quien se solicita la tenencia o el régimen de visitas. (Aguilar, 2010, p. 5-6)

De lo expuesto, se puede concluir que lo más recomendable es no romper las relaciones de comunicación de los padres con sus hijos sino recibir la ayuda psicológica de manera urgente para reestablecer y reforzar las uniones familiares con la finalidad que los menores de edad vivan de manera armónica con sus progenitores y con su familia en general.

Finalmente, se comparte la postura de la Sala Superior porque realizó una valoración conjunta de los medios probatorios como la declaración del menor, los informes psicológicos, los informes sociales, declaración de la demandada; y, sobre todo se analizó el acta de conciliación que versa en que el menor no vie con el demandante sino con el abuelo y tía paterna contraviniendo lo pactado en dicha acta; entonces, se llegó a la conclusión que efectivamente el menor de edad fue alienado provocado por el padre del menor, en la que se determinó que el menor alienado debe vivir con su madre con la finalidad de garantizar sus derechos como la identidad y a vivir en una familia y no ser separado de ella de manera arbitraria; en consecuencia, la Sala ordenó que se realicen terapias psicológicas y charlas para poder restablecer la salud mental que los padres y el menor deben realizar.

En conclusión, el padre alienante perdió la tenencia de su menor hijo al quedar demostrado que efectivamente la alienación parental; por lo que la Sala ordenó que el menor sea entregado a su madre; y, se estableció un régimen de visitas a favor del padre con la finalidad de mantener las relaciones comunicacionales entre padre e hijo.

\section{CONCLUSIONES}

1. La patria potestad pertenece únicamente a los padres, la misma que puede suspenderse por encontrarse en algunas de las causales que indica el Código de los Niños y Adolescentes.

2. La tenencia es un atributo de la patria potestad que puede ser unipersonal o compartida.

3. La alienación parental es una forma de maltrato infantil que causa violencia psicológica al menor de edad provocado por uno de sus padres.

4. Aunque exista acuerdo conciliatorio, el progenitor puede perder la tenencia si se demuestra la existencia de alienación parental.

5. Es necesario e importante acudir a terapias psicológicas y charlas de orientación para reconstruir la relación paterno-materno filial.

6. El interés superior del niño es considerado como principio, derecho y norma de procedimiento. 


\section{REFERENCIAS}

- Aguilar, A. (2010). El síndrome de alienación parental (SAP). Sus implicancias en el binomio custodia-régimen de visitas. https://dialnet.unirioja.es/descarga/articulo/3255751.pdf

- Aguilar, B. (2009). La tenencia como atributo de la patria potestad y tenencia compartida, Derecho \& Sociedad. Año XX, N³2, PUCP, 191-195.

- Chávez, S. (2018). Síndrome de alienación parental en el derecho penal peruano, como factor contra la violencia psicológica. (Tesis de maestría) Universidad Nacional Federico Villarreal, Lima, Perú. http://repositorio.unfv.edu.pe/bitstream/handle/UNFV/2702/CHAVEZ\%20 ROJAS\%20SADI\%20ANTONIO\%20-\%20MAESTRIA.pdf?sequence=1\&isAllowed=y

- Expediente. N02079-2009. Sala Primera del Tribunal Constitucional. Distrito Judicial de Lima. Fundamento jurídico 13.

- Gil, A. (2011). Acciones del sistema nacional DIF para prevenir la alienación parental: Crianza humanizada y parentalidad bientratante. Comisión Nacional de los Derechos Humanos. México. https://www.corteidh.or.cr/tablas/r28806.pdf

- El Plural (2020). El síndrome de alienación parental. El Parlamento de Catalunya contra las mujeres y la ciencia. https://tribunafeminista.elplural.com/2020/06/el-sindrome-de-alienacionparental-el-parlament-de-catalunya-contra-las-mujeres-y-la-ciencia/

- Herrera, M. (2017). Influencia del síndrome de alienación parental en la regulación del otorgamiento o variación de la tenencia de menores, Arequipa 2016. (Tesis de maestría) Universidad Andina Néstor Cáceres Velásquez, Arequipa, Perú.

- López, A. (2020). Patria potestad: alimentos. (Tesis de Maestría) Universidad de Alcalá, España. https://ebuah.uah.es/dspace/bitstream/handle/10017/46410/TFM_Lopez_Higueras_2020. pdf? sequence=1\&isAllowed=y

- Observación General №14. (2013). Derecho del niño a que su interés superior sea una consideración primordial. http://www.unicef.cl/web/informes/derechos_nino/14.pdf.

- Maida, A., Herskovic, V. \& Prado, B. (2011). Síndrome de alienación parental, Chil. Pedriat. 82 (6). http://dx.doi.org/10.4067/S0370-41062011000600002

- Rodríguez, L. (2011). Alienación parental y derechos humanos en el marco jurídico nacional. Comisión Nacional de los Derechos Humanos. https://www.corteidh.or.cr/tablas/r28806.pdf

- Ruiz, R. (2011) La llamada alienación parental: La experiencia en España. Comisión Nacional de los Derechos Humanos. https://www.corteidh.or.cr/tablas/r28806.pdf

- Varsi, E. (2012). Tratado de Derecho de Familia. Tomo III. Edit. Gaceta Jurídica.

Fecha de receptación: 12 de octubre de 2021

Fecha de aceptación: 16 de noviembre de 2021 